\title{
Unresectable Melanoma
}

National Cancer Institute

\section{Source}

National Cancer Institute. Unresectable Melanoma. NCI Thesaurus. Code C148517.

Melanoma which is not amenable to surgical resection. 